\title{
PROPOSED CANADIAN FOREST EDUCATION STUDY ${ }^{1}$.
}

By K. G. FENSOM

Consulting Wood Products Engineer, Montreal, 2uebec

I N 1909 a conference was held in Washington to consider and analyse the status, character, scope and adequacy of professional training in forestry. One of the members of the Committee on Forest Education appointed at that time was Dr. B. E. Fernow, then Dean of the Faculty of Forestry, University of Toronto, and the report which was tabled two years later at a second conference dealt with conditions both in the United States and in Canada.

In the years following that educational conference many factors have exerted a profound influence on the development of forestry. In Canada as in the United States there has been a notable growth in teaching facilities. The scientific data which have been accumulated have provided better material for instruction. Technically trained personnel has greatly increased. The field of employment for foresters has broadened. Research and experience have exposed fundamental economic relationships, the interpretation of which has tested the ingenuity of forest educators. Depression and two world wars have created various elements which have complicated the problems of forestry. Although the 1911 predictions as to future trends were remarkably accurate, the authors could not be expected to foresee the whole panorama of a profession adjusting itself to these changing conditions.

Many innovations have been introduced by forest educationists in Canada to meet these changed conditions but since 1911 there have been no over-all surveys nor forest education inquiries conducted on a national basis. In the United States, during this same period, there was a conference of forest educators at New Haven in 1920 under the auspices of the Yale School of Forestry when such items were considered as the purposes and structure of a general four-year course, the functions of a five-year course, the problems of specialization, and the place and character of vocational training suited to American conditions. Then, a few years later, the Carnegie Corporation made a grant to the Society of American Foresters for an intensive study of all phases of forest education. This study culminated in the publication in November, 1932, of that notable work by Henry S. Graves and Cedric H. Guise. This analytical study has become a standard text-book on forest education and has contributed to many vital reforms and adjustments.

Conditions in Canada and in the United States are comparable in many respects, but they are not so comparable that the results of investigations planned for application in the United States can be applied with equal validity in Canada. Problems peculiar to Canada can be solved only by special study

1This is part of a report of the Forest Edueation Committee of the C.S.F.E. to be tabled at the annual meeting of the Society in February, 1947. 
of Canadian conditions. This is true of problems of forest education as of other problems, and there is no doubt but that an intensive analysis of the whole field of forest education in Canada would be as productive of vital information as was the survey of 1909-1911, that it would contribute towards standardization of educational requirements, and that it would give valuable direction to future planning.

Much of the argument concerning forest school curricula has to do with the degree and diversification of specialist training. Quoted from the Forestry Quarterly, Vol. 10, No. 3, 1912, the Committee on Forest Education expressed the following opinion:-

"At present, however, the time has not come for such specialization, and the forest schools must aim to give a well-balanced general training in forestry proper, perhaps with a little more emphasis on either silvicultural work, or forest engineering, chiefly lumbering. Any tendency, however, to increase the training along any of these specialized lines within the four-year course must necessarily be done at the expense of the other subjects, or else the number of years required for this training must be increased. The scope of the courses considered here has in view a well-balanced professional school which does not aim at great specialization in any of these three lines of work, but attempts to give a general knowledge of the principles which underlie the 'entire field of the foresters' activities, leaving the acquisition of special knowledge to be gained by the students in actual business life, or after graduation from the forest schools, or by special study".

It would be just as relevant to declare against the encroaching dangers of specialization now as it was then. But this danger is much more than a conflict or a choice between two or more different kinds of forestry training. It is basically a conflict between two fundamental concepts of educationthe Jeffersonian, which states that the prime responsibility of educators is to discover the gifted student and train him for leadership in his special field; and the Jacksonian, which emphasizes the primary duty of educationists as a concerted effort to raise the level of the masses. Both these concepts can and must be part of the complete educational pattern. But more and more educationists today are becoming apprehensive that Jeffersonian specialization has run away from and far out-distanced the Jacksonian philosophy. Modern day learning has spread out to encompass everything from radar to the private life of a snail - and that body of tradition and culture which provides a common meeting ground for all men has been receiving less and less attention.

Permanent peace in a nation and among nations must stem from under: standing between groups and individuals, and this understanding cannot develop to the fullest possible extent unless there be a sharing of a common body of knowledge and ideas, a common training in the analysis of values and relationships, and a sharing of the awareness of the importance of ideals and objectives. Only a liberal education can provide these fundamentals of citizenship and understanding. 
In this age of specialism the majority of students at the university level are studying for a specialized career-whether as doctor, lawyer, forester, or engineer. A great deal of time and concentration are demanded of the student who aims to master any particular segment of learning. As achievement in these special fields of learning is the equivalent of job preparation it follows that material advancement in our social structure depends in large measure on the kind of training received.

It is natural, therefore, that the high pressures of our modern society should have created an impatience and a desire to eliminate anything in educational procedure which-does not contribute directly to the material ob. jective.

The increasing urgency of the demand for special training accentuates the need for general education as a balance in all fields of specialism, and this need is no less in forestry than in engineering or medicine or the other older professions. It is not the abolition of specialization which should be considered but the interweaving of a properly balanced liberal education with all types of special training.

What, then, is the ideal mixture? The cramming of a broad general course in forestry plus specialization plus adequate attention to the humanities over a span of four college years would seem to verge on the impossible, yet there must be some means of attaining or at least approximating what few will dispute is an educational ideal. A five-year or even a six-year undergraduate course might be advocated but not many of the kind of students who are attracted to forestry could afford to spend this extra time at college. Perhaps these longer courses could be given in special circumstances at the better equipped colleges, or perhaps graduate study facilities might be made available where there were adequate accommodation, staff, and financial support.

Another field which can and should be investigated is that of high school education, particularly from the standpoint as to how this pre-university training can be improved and standardized so as to give sound grounding in the humanities and a better grasp of certain types of elementary subjects which frequently have to be "brushed-up" at the university. There are certain features common to all high school systems across Canada, certain other features which are variable in the different provinces, and not a few which are variable within a province. These differences and similarities would have to be analyzed in respect to both the present and potential standards of preparatory work required by the different forest schools. If the forest schools could influence the kind of training which the pre-university student receives so much the better; but the high school, specializing as it so frequently does and too often dominated by narrowly defined college entrance requirements, provides student units for every educational pattern. It cannot, therefore, be expected to cater to the specific requirements of a comparatively small profession excepting within the context of the composite requirements of all the different professions, sciences and arts. Nevertheless it should be possible to define more or less precisely what is the desired relationship between uni- 
versity forestry requirements and the high school curriculum-and not in terms of matriculation but in the substance of courses throughout the period of high school education. The most desirable adjustment is that high schools should be equipped to carry more of the educational load than they do, especially as regards the proper distribution of a liberal education throughout all kinds of studies. If these adjustments were made the forest schools would have valuable hours to allocate to essentials which of hard necessity sometimes receive too little attention.

This year a seven-person team of representative American educationists was appointed by the Educational Policies Commission of the United States to study the whole elementary school system in the United States for the purpose of blueprinting post-war objectives. While the report of the Survey Committee of the Canada and Newfoundland Education Association (since August, 1946, the Canadian Education Association) published in March, 1943, constitutes an up-to-date blueprint for Canadian secondary education in respect to all the broad principles involved it does not attempt to define the ideal relationships between university and high school requirements, and it is to be hoped that further and more detailed studies will be undertaken along these lines.

It should be remembered that the authors of the 1911 report had in mind only two main specialist sub-divisions. Today there are dozens of possible specialist combinations and an indefinite number of potential job opportunities for the students of those combinations. There may be differences of opinion as to the mechanics involved in mastering these varied branches of learning, but surely it must be agreed that any specialization which will contribute to the development of the profession and advance the cause of forestry is part of the over-all forestry pattern and should, therefore, be considered in some phase of university training.

Most educationists agree that early specialization should not be encouraged, that concentration in specific directions should be attempted only dur. ing the latter years of an undergraduate course, or that it should be the subject of special graduate studies. Just as specialization at the proper time will broaden the opportunitics for employment so will specialization at the wrong time narrow the opportunities for employment. If a student has sufficient time to find himself and to discover (or to have discovered for him) his particular aptitudes and interests, he is not so likely to make a mistake in his choice of a specialty. Nor, having made that mistake and when he has had broad training in all the essential fundamentals, is he precluded from the practice of some other phase of forestry. This also applies to a student who is unable to find employment in his specialty and whose basic training in the general principles of forestry still qualifies him for alternative employment. The disadvantages of specialization if undertaken at the expense of a general education in forestry are apt to cancel off any advantages, and consequently the balancing of all determinative factors requires expert judgment. It also involves the application and analysis of data which cannot be collected readily excepting by a body set-up 
for that purpose which would have the time; opportunity and financial resources to thoroughly canvass the field.

Such a body would be able to compile information indicative of the advisability or otherwise of organizing special curricula for undergraduate studies in fields closely allied to forestry, as, for instance, wood technology, forest pathology, logging engineering, wood chemistry, irrigation and drain. age, land economics, business administration, kiln-drying, wood preservation, ecology, forest entolomogy, and so on. These curricula, although possibly inclusive of some straight forestry courses, would embrace very little technical forestry training, and graduates would therefore not qualify for rating as professional foresters. They would, however, be entitled to their own special kind of classification as wood technologists, kiln-drying experts, logging engineers, etc., and the degree which they would receive would presumably be so designated as to avoid any possible misunderstanding in it's interpretation.

It can be assumed that there is either an existing field of employment for graduates as above who are not foresters or that a demand for this kind of trained personnel could be created. Prior to any organization of courses, however, there would need to be a careful evaluation of job chances. There would also need to be an appraisal of whether the requirements of given situations would seem to demand foresters with specialized training or graduates in the specialties themselves. Logging engineers, for instance, might be foresters with additional engineering training in the techniques of logging, or they might be graduates of special logging courses. A third alternative is that they might be graduate engineers with post-graduate training in selected forestry subjects. In fact this third alternative is one applicable to a wide range of subjects, and there is no doubt but that post-graduate training in some phase of forestry superimposed upon graduate training in engineering, agriculture, or other of the sciences would provide the basic theoretical experience for many different kinds of specialized work. There is a place for all these different forms of training; but only according to systematic interlocking plans which would ensure the avoidance of duplication, competition and wasteful effort, and in the carrying out of which both forest schools and other faculties would co-operate.

No categorical statement can be made as to the most desirable distribution of special forestry courses through the courses of other faculties, but it would seem that most, if not all, agricultural students should be given some training in forestry-perhaps through the medium of a Chair of Forestry established for that purpose, perhaps by means of an arrangement with one of the existing forest schools. Only a comparatively small percentage of the total engineering and general science students need or want to have special forestry training, but that small percentage is an important fraction of the whole and every effort should be made to determine where and under what conditions this training could be best provided. 
All these and other factors should be studied in relation to the requirements of forestry in Canada and the individual requirements of each forest school. The objectives of the proposed study would be to collate data, to indicate the relationships between different factors, to discuss the issues involved, and to draw certain general conclusions. It would be the responsibility of those conducting the study to indicate principles, potentials and limitations. It would not, however, be their responsibility to formulate specific curricula nor to suggest that standardization could invariably be effected without sacrifice of some unique functions of individual forest schools. Forest schools, as are the universities of which they are a part, to a large extent are fashioned by local conditions, by the preference and opinions of their personnel, by the character and pre-university training of the average undergraduate body, by the adequateness or otherwise of the financial support received, and by the particular forestry requirements of the province in which they are situated. For these reasons the effectiveness of a forest school does not depend wholly on how closely it's curriculum comes to some theoretical standard. Other criteria are the ability of graduates to cope with the problems of forestry over a period of time, methods of teaching, general educational policies, and the extent to which the school is susceptible to reasonably rapid adjustment. Usually the theoretical standard is an ideal which, because of certain practical limitations, seldom if ever is realized in actual practice. Nevertheless it is essential that a broad theoretical standard be defined, so that direction can be maintained no matter what are the prctical limitations. .

It is not thought that the proposed study would be sufficiently productive of worthwhile results unless undertaken as a full-time project over a period of at least one year by qualified and interested personnel. This project would involve the development and distribution of questionnaires. It would involve a tremendous amount of correspondence, conferences and interviews. It would involve intensive studies of the past, present and potential occupational activities of foresters, and an analysis of the relationship between supply and demand in respect of each occupation. This analysis would need to be backgrounded against the history of forestry in Canada-it's problems, evolution, scope, character and decisive trends. There would need to be a compilation as to the characteristics, facilities, policies, development, problems, and graduate and undergraduate records of all forest schools. All this in turn would need to be synchronized against the educational program as such and the various pros and cons of this or that emphasis in any given direction. This project could not be undertaken either comprehensively or thoroughly as either an honourary or as a part-time responsibility. Nor could it be done excepting under the auspices of a national body equally concerned with the problems of forest education in all parts of Canada, and able by reason of its national status to take a thoroughly objective view of each of the many components which contribute to the whole. That is why it would seem best that these ends be achieved, if passible, under the sponsorship of the Canadian Society of Forest Engineers. 
The future of the profession depends on the basic training of the forester. Foresters should make contact with almost every phase of economic and natural life. They are concerned with research, with animals, with plants, with the production and utilization of all wild land crops. Within their scope should come the care and protection of soil, waters, and scenery; the development of logging techniques; aerial operations; transportation; surveys; marketing; taxation; and public relations. The problems of Canadian conservation generally and the most efficient use of the raw materials of the forest demand the services of highly trained technical forestry personnel; but unfortunately many foresters have not had the kind of basic training which would qualify them as specialists, and consequently their field of job application is limited. This is one of the chief reasons why foresters as a professional group have not made a bigger impact on the public, and why it is incumbent upon the profession to be vitally concerned with the complex problems of forest education. 